\title{
Solution for Cardioplegia Dosage Form
}

National Cancer Institute

\section{Source}

National Cancer Institute. Solution for Cardioplegia Dosage Form. NCI Thesaurus. Code C149903.

Liquid sterile preparation consisting of an aqueous solution intended for use in inducing cardiac arrest during heart surgery. Some preparations may require mixing with other preparations prior to administration, for example to adjust the $\mathrm{pH}$. 